\title{
Emilio Adolfo Westphalen y la crítica de arte ${ }^{1}$
}

Alfonso Castrillón Vizcarra

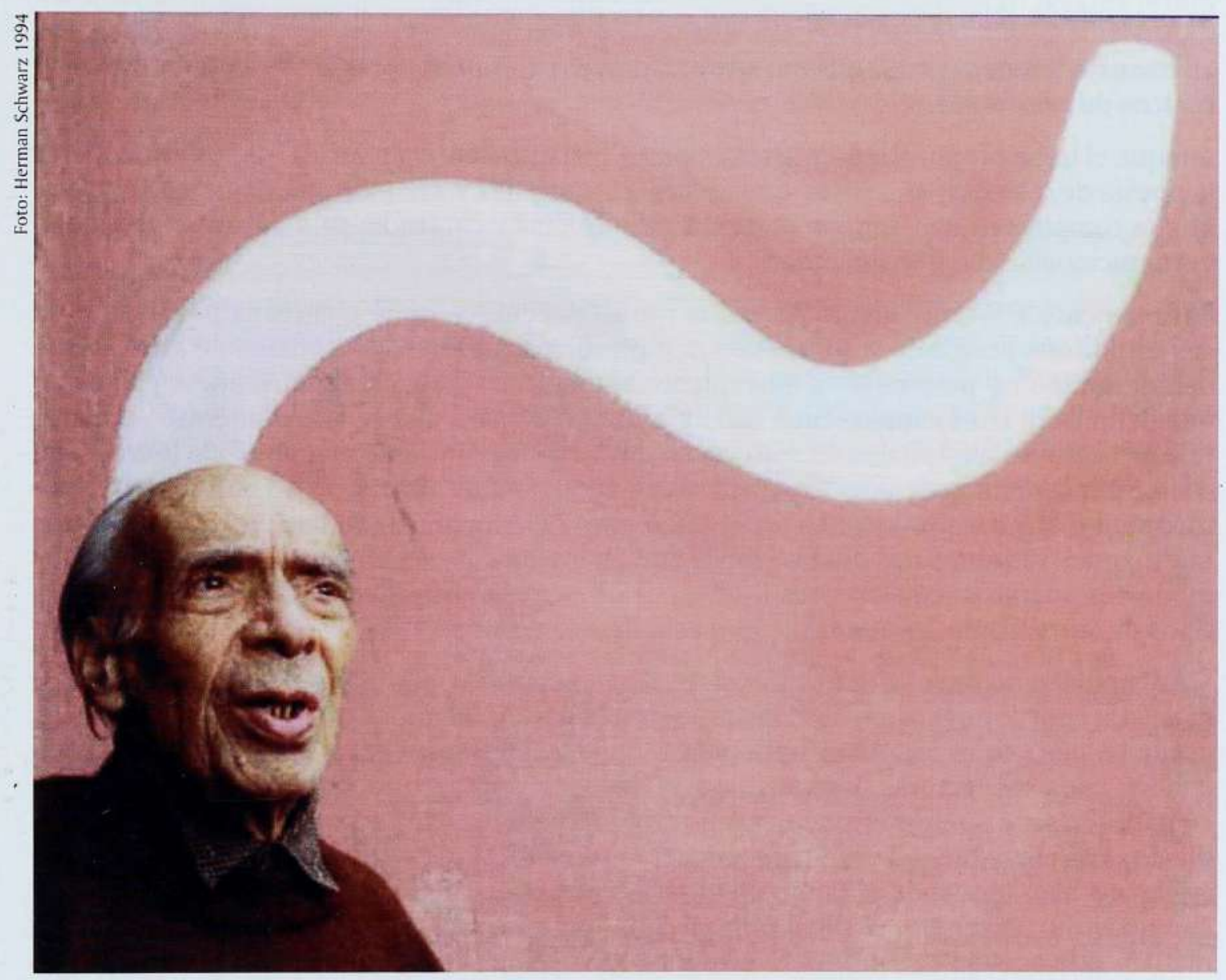

Emilio Adolfo Westphalen es un poeta difícil, no solo por su hermetismo, sino por las incógnitas que sigue planteando a la crítica en cuanto nos disponemos a indagar acerca de él, su condición de poeta por ejemplo, o cuando nos preguntamos en qué tendencia literaria podemos ubicarlo. Acercarse a un poeta y crítico como Westphalen, supone siempre una intromisión, aunque indispensable para indagar su mundo, con los pocos elementos de que disponen quienes leen sus obras. Tratándose de una persona tan reservada como fue Westphalen, publicar un poemario en 1933 significó para él ponerse en evidencia

1 Texto leído en el Coloquio Internacional "Westphalen: Abolición del silencio", el 12 de julio de 2011, en la Pontificia Universidad Católica de Lima. Esta versión ha sido corregida y aumentada. 
frente al público y ese hecho quizás se inmiscuía en su vida íntima y tranquila². También le incomodaba el apelativo de poeta, artista, al fin y al cabo que, en aquellos años equivalía a bohemio. Su afilada inteligencia comprendía estos condicionamientos cuando se trataba de los artistas sobre los que escribía, pero en su caso no sé si consistía en una exagerada modestia o una incontrolable timidez ${ }^{3}$.

Confieso que lo conocí, casualmente, una tarde en un aula de la Universidad de San Marcos y que fue imposible mantener un diálogo de dos minutos siquiera, fuera de las fórmulas habituales de cortesía. Así era, callado y distante con los desconocidos, pero me dicen que cuando se encontraba con los amigos se explayaba a gusto.

Menciono el episodio de mi encuentro con él para destacar que mi acercamiento a Westphalen ha sido a través de sus escritos exclusivamente. Puedo decir que su obra se me ha presentado sola, defendiéndose con sus recursos más finos y misteriosos.

Es con este temperamento que me atrevo a presentarles unas notas sobre algunos artículos críticos de Westphalen.

Aunque el tema propuesto para esta sesión es "Westphalen y la plástica”, no podría separar la poesía de los ensayos críticos que dedica a los artistas y a la pintura. Me parece que ambos se complementan y forman parte del mundo dual y contradictorio del autor, del juego entre racionalidad e irracionalidad.

Posiblemente a Westphalen le parecería intrascendente la duda planteada por alguno de sus estudiosos acerca de si su poesía era o no surrealista. Hay varios casos de artistas que han declarado no pertenecer a movimiento alguno por el hecho de no sentirse presos en una definición: Por ejemplo, Tilsa Tsuchiya que no admitía que se la considerase surrealista. En el caso de Westphalen, el solo hecho de declararse un "intermediario" de la creación, o suscribir la opinión de que "El artista ocupa un lugar muy modesto" ${ }^{4}$ en ella, lo acerca notoriamente al Surrealismo y nos recuerda el paso del Manifiesto de Breton: " (...) nosotros que en nuestras obras nos hemos convertido en los sordos receptáculos de tantos ecos, los modestos aparatos registradores (...)" ${ }^{\prime \prime}$.. Si no se deja encasillar en alguno de los varios tipos de surrealismo, es admisible que está dentro de su espíritu.

Si Westphalen no se consideró surrealista, sí se encontró cómodo frente a ciertas actitudes dadaístas, por lo menos en sus dos primeros libros. Alguien pensará que esta afirmación es nimia, pero no es así. Ante todo, pienso que hay consenso en aceptar que Westphalen conocía, por sus lecturas, las vanguardias dadaísta y surrealista. Por otro lado si leemos cuidadosamente su primer poemario nos daremos cuenta de la particular manera de emplear las palabras fuera de toda preocupación semántica. Así el primer poema que abre Las insulas extrañas (Andando el tiempo) es una enumeración de situaciones que tienen que ver con un ritmo acelerado, el tiempo moderno, donde se intercalan versos por demás enigmáticos que ocultan su sentido. Es evidente que un sujeto -el poeta- dice algo, lo primero que se le viene a la memoria, o lo que de casualidad ven sus ojos inestables de observador

2 En una de sus presentaciones en público Westphalen comenzó su lectura:"Me hubiera sido muy grato y alentador reunirme con ustedes hoy día y agradecer a cada uno su asistencia y simpatía. Pero hace algún tiempo tuve una experiencia desagradable que me hizo comprobar cuánto me alteraban las manifestaciones de aprecio y de afecto (sobre todo si eran colectivas). Perdía entonces el control de mí mismo y ponía al descubierto una sensibilidad excesiva e intolerable para quien prefiere ser recatado en cuanto a su intimidad". Westphalen, Emilio A. 1997. "Un poema auténtico es imprevisible e irrepetible", en Escritos varios sobre arte y poesía. Lima: Fondo de Cultura Económica, p. 183.

3 Westphalen fue una persona extremadamente sensible. Últimamente me ha sido referido por un testigo presencial que, en la primera década de 1980, fue invitado a Florencia para dictar una charla, motivo por el que viajó especialmente. Al comenzarla evocó el nombre de su esposa Judith, fallecida en Roma, lo que fue suficiente para que se le quebrase la voz y tuvieran que suspender la conferencia. Westphalen cita a Paul Klee, Op. cit, p. 149.

5 Nadeau, Maurice. 1964. Histoire du surréalisme. Paris: Éditions du Seuil. p. 53. 
nervioso. El lector no encontrará en el poema el sentido tradicional con que percibe un mensaje razonable, es decir el poema como transmisor de ideas y emociones, sino un caudal de palabras, donde no se tiene en cuenta el todo, sino las partes. Esta desarticulación privilegia la palabra concreta, las pequeñas frases en sí, como trozos individuales que afirman su suficiencia. El poema no busca pues ritmo, ni belleza en las metáforas (aunque hay algunas excepciones) y los versos son ásperos y duros, pero eso lo tiene sin cuidado a Westphalen que busca una ruptura total con la tradición poética después de Vallejo. Comentando a Lautréamont Westphalen había dicho "cómo puede ser que sin significado profundo pueda afectarnos?" En fin, pienso que su pequeña nota titulada "Surrealismo a la distancia", es bastante esclarecedora en cuanto al grado y la forma de su adhesión al movimiento creado por Breton.

He querido aludir desde el comienzo al recurso dadaísta de lo irracional en los dos primeros libros de Westphalen, para contraponerlos a sus textos críticos: frente al torrente de "escritura automática" de su primera poesía, su crítica de arte demuestra un pensamiento cuidadosamente elaborado y coherente que deja ver lo que piensa sobre el arte contemporáneo y peruano.

\section{Westphalen crítico de arte}

Si consideramos la crítica de arte como un género literario, pariente cercano del ensayo, no cabe duda de que Westphalen ha sido uno de los más lúcidos y penetrantes, ejerciéndola, es cierto esporádicamente en forma de notas y presentaciones leídas y artículos en revistas especializadas, nunca, que yo sepa, dentro del ritmo apremiante de los periódicos. La mayoría de sus artículos, publicados en las revistas que él dirigió (Las Moradas, Revista Nacional de Cultura, Amaru) están dedicados a la literatura y relativamente pocos a la plástica: en esto tenía que ver, por encima de todo, su gusto personal, en torno a unos cuantos casos individuales, abstraídos del proceso del arte en el Perú.

Para comprender sobre qué bases estéticas se manifiesta la crítica de arte de Westphalen, conviene incluir en el examen sus textos sobre literatura, de donde resulta el pensamiento de Westphalen sobre el arte en general.

La lectura de Lautréamont ${ }^{7}$ impresionó fuertemente al joven Westphalen; lo inmovilizó, impidiéndole hacer un análisis y emitir un juicio. Concluye: la obra de arte es inalcanzable y termina siendo un misterio. Hay que agregar, además, su desconfianza en la palabra, "instrumento rudimentario" con que tratamos de asir lo vivo ${ }^{8}$. Esta primera opinión sobre el autor de los Cantos de Maldoror arroja dos ideas que deben tenerse en cuenta, la primera sobre el culto al genio; y la segunda sobre cierto pesimismo crítico que nos impide razonar sobre el "misterio" de la obra de arte. Así, el genio es el único capaz de una "originalidad absoluta" y el crítico resulta invalidado de dar una explicación razonable. Por otro lado Westphalen está convencido del papel de la inspiración en la creación artística y esto tiene que ver con sus propios estados de ánimo, como cuando confiesa en una conferencia sobre César Moro "Ocurre que no he logrado ponerme en trance de escritura", es decir, cuando no alcanzaba cierta disposición no era posible aventurarse por los caminos de la creación. Pero, en consonancia con los surrealistas, admite que no todo es trance, inspiración, (impulso primero); estados que se pueden provocar, "forzar", sin dejar de lado "la atención consciente", el "conocimiento" y "el estudio", para terminar diciendo "no hay arte de la

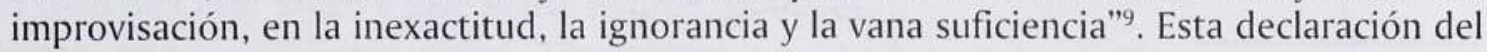

9 Westphalen, Emilio A. Nota sobre Ezra Pound y T. S. Eliot, en Op. cit. p. 105. Artículo publicado en Las Moradas, Lima, Vol. I, No3, diciembre 1947, enero 1948. 
año 1947, echa luz sobre su posición, tantas veces discutida, sobre la "escritura automática" en sus dos primeros poemarios y en todo caso la contradicen.

Otro tema que conviene examinar es el de su "condición de poeta". A Westphalen le incomodaba que lo llamaran "poeta", no sólo porque él creía que su papel era el de transcriptor o intermediario de algunas ideas o emociones convertidas en poesía; tampoco porque su "período de disponibilidad completa para la poesía" fue "relativamente corto" de 1929 a 1934; sino por "las asociaciones solapadas de menosprecio" respecto a los poetas, o porque en los años 20-30 "era mal visto dedicarse a la poesía"

Cuenta Westphalen que estando por terminar el colegio un compañero suyo le dijo en un exabrupto "Tú vas a ser poeta", frase que lo hizo recelar de "las implicaciones peyorativas -por no decir despectivas- del mensaje: una manera de decirle "que era un don Nadie, una persona inocua y despreciable". Episodio juvenil que aparecerá amenazante luego de sus dos primeras entregas poéticas y, quizás por este motivo, dejó de hacer poesía por tantos años y prefirió el ensayo crítico que connotaba una práctica más académica y posiblemente prestigiosa. Además Westphalen nunca se sintió "hombre de profesiones" 11 , abriendo con esta declaración un tema bastante interesante: la poesía no puede ser asunto de profesionales pues es una "condición". Esta afirmación se apoya en sus mismas declaraciones cuando dice que su "papel dentro de la poesía peruana ha sido aleatorio y que ha dependido mayormente de las circunstancias"12. Todo esto lo lleva a proponer la desaparición del poeta y a la despersonalización de la poesía: “...no estaba equivocado Lautréamont -dice Westphalen- al pedir que la poesía fuera hecha por todos", y termina proponiendo "que se volviera costumbre publicar anónimamente toda poesía"13.

Así pues, resumiendo, Westphalen antes de encarar el tema de la crítica de artes plásticas ha podido elaborar una estética que se basa en la creación como acto genial, que fluye gracias a la inspiración pero bajo la atenta vigilancia de la razón, (contrariamente al propio ejercicio poético de sus dos primeros libros); en una desconfianza en la palabra tan poco apta para dar cuenta de la vida interior y que genera un "pesimismo crítico" que nos impide razonar sobre la esencia poética. Por fin, en 1974, propone despersonalizar la poesía y llegar al anonimato.

\section{Westphalen, crítico de artes plásticas}

En la edición de Escritos varios sobre arte y poesía del Fondo de Cultura Económica, 1997, no se si está reunida toda la obra de Westphalen, pero sí una buena parte que llega a más de 400 páginas. La primera está dedicada a la literatura; la segunda a las artes plásticas y la tercera a temas varios. En la segunda, que es la que nos interesa ahora, dedica seis artículos a la teoría del arte moderno y luego comenta la obra de seis artistas peruanos y un extranjero. Es, pues, comprensible que en esta oportunidad sólo veamos los más representativos.

En su artículo "Teoría del arte contemporáneo", Westphalen busca, de manera velada y un tanto oscura, el camino para estructurar una teoría que dé cuenta de los cambios sucedidos en el arte moderno. Aquí distingue entre "la necesidad de expresión por el arte que tan tempranamente y de manera tan general nos acoge a todos"14 y por otro lado "descubrir en qué manera por el arte ha cambiado (o puede cambiar) nuestra vida"15. En medio incluye

10 Prejuicios extensivos en Lima a pintores y músicos. "Conversaciones con Nedda Anhalt", en Westphalen, Emilio A. 2004. Poesía completa y ensayos escogidos, Lima: Pontificia Universidad Católica del Perú. p. 647.

11 Westphalen, Emilio A. 1996. Escritos varios sobre arte y poesía. Lima: Fondo de Cultura Económica, p. 137.

12 Op. cit. p. 145.

13 Op. cit. p. 146.

14 Es decir-explico- las cualidades que pueden tener los seres humanos para percibir lo bello.

15 Interpreto: la atribución de propiedades éticas al arte en el sentido tradicional clásico de "lo bello es bueno". 
un largo paréntesis donde cuenta la anécdota de la niña que ordena las flores en el camino y que, si me permiten, dice: "(Nos viene aquí el recuerdo conmovido de una pequeña que ponía sus pies sobre la tierra todavía con gran indecisión, pero ya había dado en un juego maravilloso sumamente absurdo y poético: todo hueco o rendija que descubría por el suelo quería ornar con un ramito de flores marchitas, o de pobres ramillas donde sólo una que otra hoja decía de la especie vegetal a que pertenecían, y nada nos enseñó más cómo el arte es un propósito, tal vez descabellado, pero que brota de nuestro venero más recóndito, que ya está en acción cuando el pensamiento no acierta a formularse, que este plantío ideal que incansablemente disponía la niñita.)" Con esta anécdota Westphalen quiere significar cómo el sentido artístico está presente en los niños, aún antes de que comprendan lo que están haciendo, pero confunde lo estético con lo artístico, equívoco generalizado en el mundo del arte y extensivo a las obras de los aficionados y los alienados.

Los párrafos que siguen están teñidos por las vivencias personales de Westphalen, la cotidianeidad anodina o la presencia constante de la muerte en las noticias que venían de Europa y que le hacen decir que "al comienzo de la última guerra no veíamos más que unas ráfagas lacerantes que llegaban de un horizonte lejano, donde también resonaban unos ecos desgarradores". Esta juventud que había "creído en un mundo posible donde las alegrías podían compartirse", no sabía a dónde mirar.

Es aquí que se despierta en él una conciencia atenta a lo que está pasando en Europa y a las transformaciones sociales que ciertamente no fueron las deseadas por su generación: "Un rezago de sumisión a ciertas doctrinas nos retenía en el error de considerar las actividades artísticas -en general las culturales- "como simple coronamiento o añadidura de un edificio social erguido sobre grandiosas bases económicas y políticas". No dice qué doctrinas, pero se sobrentiende que son las materialistas.

Westphalen confiesa haber recibido una "sacudida" después de su contacto con Wolfgang Paalen, el artista y teórico, ligado en un primer momento al surrealismo, de quien leyó algunos artículos en la revista DYN y a cuyas ideas adhiere, sobre todo cuando dice "La obra de arte NO ES ni ha sido nunca una superestructura", aduciendo que ya desde la época de la prehistoria y antes del marxismo, el hombre produjo "un arte cuya fuerza de expresión no ha sido nunca superado"16. Pero esta disconformidad con el materialismo dialéctico termina con una idea de Paalen que Westphalen suscribe y que se expresa así: "El artista de nuestro tiempo sólo puede ser auténtico cuando es original", es decir una idea que, contradictoriamente, invita a entrar en la carrera competitiva del mercado que quiere obras siempre nuevas que satisfagan el ansia de consumo ${ }^{17}$.

Así, según Westphalen el arte moderno ha sido "el arte de los experimentos, de las hipótesis audaces, de las exploraciones sin fin por los terrenos más apartados, por los nunca traficados". Aunque nos pese "este arte moderno es el arte nuestro y ya no hay modo de echarlo", dice Westphalen con una pizca de ironía, y, además, debemos estarle agradecidos porque, en medio de este mundo pleno de conflictos, "el arte moderno es un manifiesto perenne de libertad, de expresión de todas las facultades, de generosidad y de entusiasmo". Sin embargo, de este panorama idealista está ausente la especulación del mercado artístico, los precios, la moda, el consumo, etc. Y el arte que se hacía en el Perú entonces.

\section{El caso de César Moro y José María Eguren, pintores}

Como apuntamos líneas arriba, Westphalen se ocupó en sus artículos críticos de unos pocos artistas plásticos peruanos entre los que figuran Ricardo Grau, Fernando de Szyszlo, Rodríguez Larraín, Ramiro Llona, César Moro y José María Eguren. Debido al tiempo

16 Op. cit. p.235.

17 Entiendo la autenticidad como un estado moral de ser fiel por convicción a cualquier modo, estilo, manera -aún del pasado- con tal de que sea buen arte o buena pintura. 
excesivo que tomaría tratar sobre las apreciaciones de Westphalen sobre cada uno de ellos, hoy día sólo quisiera referirme al caso de los dos últimos porque dan motivo a ciertas especulaciones teóricas.

Se puede decir que el mayor énfasis de la crítica de Westphalen está puesto en el carácter reivindicativo de sus escritos y la defensa de dos poetas como César Moro y José María Eguren que alguna vez se dedicaron a la pintura. Cuando trató de otros pintores es cierto que abordó el tema desde el punto de vista formal, de sus ideas, de sus etapas y sus logros, pero el ahínco y la pasión que puso en los casos de Moro y Eguren son de llamar la atención y nos obliga a explicarlos de alguna manera.

Westphalen conoce a Moro en 1934, es decir un año después de la publicación de su primer poemario Las ínsulas extrañas, y un año antes de Abolición de la muerte, su segunda entrega. Desde entonces se frecuentaron casi diariamente e iniciaron una sólida amistad hasta la muerte de Moro en 1956. La llegada de éste a Lima sin duda deslumbró al mundillo intelectual de entonces, especialmente a Westphalen que tenía 23 años. Es de suponer que Moro informase al amigo sobre sus contactos con los dadaístas y surrealistas y en general sobre la intensa vida cultural parisina y que Westphalen, por otra parte, secundase sus osadas intervenciones en la pequeña capital que era Lima entonces, me refiero a la Exposición de la Academia Alzedo (1935) y el manifiesto contra Huidobro (1936).

En vida de Moro Westphalen publicó solo una pequeña nota sobre su poemario Le Chateau de Grisou ${ }^{18}$; pero después de su muerte inicia una cruzada a favor del amigo frente a la amenaza del olvido. Al comenzar su artículo "Nota sobre César Moro", de 1965, dice:

"Los nueve años transcurridos desde el 10 de enero de 1956, día en que muriera César Moro, no han bastado para que el público pudiera adquirir una visión más o menos fidedigna de su obra ni para que la crítica intentara una apreciación más o menos bien fundada".

En el caso de Moro poeta me parecen justos y acertados los juicios que Westphalen vierte en sus artículos: una poesía como la suya, aunque escrita en francés (salvo "La tortuga ecuestre") que merecía ser develada y reconocida, y puesta al lado de J. M. Eguren y de Vallejo, como un caso interesante del alcance de las vanguardias en América. Pero en relación a su pintura me parece que se deja llevar por el afecto, movido quizás por la amistad incondicional que le profesaba. Moro era sin duda un hombre dotado de gran sensibilidad para las artes, pero disperso en cuanto a sus elecciones, la poesía, la pintura y también la danza. Si en Lima ensayó la ilustración con finos trazos Art Nouveau o Art Deco, la ausencia de una datación segura de sus obras hace imposible el seguimiento estilístico de Moro en París y saber cuándo empezaron sus tanteos no figurativos, más bien gestuales, que culminaron más tarde en la opción geométrica (estando ya de regreso en Lima) de los pasteles de $1954^{19}$. Es extraño que al entrar en contacto con los surrealistas no haya intentado la figuración de tipo onírico, más afín a su poesía, como los trabajos de De Chirico, Magritte o Delvaux. Una explicación puede ser que este tipo de pintura es fruto de cierto oficio o escuela, que Moro no tenía, por lo que intentó la no figuración, más espontánea, improvisada e irracional. Lo que ha quedado de su obra -la mayor parte témperas de pequeño formato sobre papel- son ensayos, experimentos que no maduraron, testigos de una intensa búsqueda sin norte ni definición.

18 La Prensa, Lima, 20 de febrero de 1944.

19 Una buena ocasión para ver los trabajos de Moro en Lima fue la exposición "Con los anteojos de azufre. César Moro artista plástico", (Embajada de España y Agencia Española de Cooperación Internacional, Lima, 2000) Queda el catálogo de esta exposición de gran utilidad para el estudio de los ensayos plásticos de Moro, aunque dificultado por la ausencia de algunas fechas. Respecto a la pintura de Moro se han dicho cosas por demás exageradas comparándolo incluso con Aubrey Beardsley. Mariela Dreyfus. 2008. Soberanía y transgresión: César Moro. Lima: Editorial Universitaria URP, 
Westphalen se lamenta de que el medio limeño no reconociera en su momento a Moro, pero es comprensible esta inadvertencia ya que el poeta realizó una exposición en Lima, que tuvo visos de escándalo dadaísta en 1935, y otra individual en la Peña Pancho Fierro en 1937 y luego partió para México. Por otro lado hay que tener presente que a Moro no le interesó darse a conocer y que practicó la poesía y la pintura como "actos gratuitos". El mismo Westphalen dice que Moro "no ha demostrado ambiciones de "hacer carrera" y transcribe unas líneas del poeta que dicen: “...se trata de pintar para sí y nada más” (...) "Pintar es tan divertido como puede ser, a veces, barrer" 20 Pero sin duda esta declaración no es sino una boutade ; pronto se da cuenta de su real condición y el desaliento lo alcanza: "Todo es difícil en la pintura, -le escribe a Westphalen- sobre todo para mí que jamás he tenido facilidad. No es modestia, quizás tenga otras cosas mejores que facilidad, pero facilidad no"21.

Lo mismo sucede con José .María Eguren de quien dirá: "Se buscará en vano el nombre de José María Eguren en los libros publicados sobre arte de este siglo en el Perú" 22 , y acierta al decir que el silencio se debe quizás a que Eguren actuó fuera del circuito artístico y también al "desinterés de mostrar su obra fuera de sus amigos y los visitantes que se lo solicitaban". Esto es importante porque ¿un artista que no entra al circuito cómo puede pretender que se lo considere y que figure en la historia del arte peruano? Me parece pues un tanto excesivo concluir que Eguren como pintor, "en una época de confusión y prejuicios dañinos para la expresión plástica supo hacer arte verdadero y (...) acorde con las exigencias vitales y estéticas de su tiempo". Respecto a esta última frase debo hacer recordar que en todo caso los escasos óleos de Eguren -con sus indudables méritos estéticos-pueden situarse dentro de una visión realista-impresionista, muy lejana de las inquietudes artísticas y temáticas del arte peruano de la década del $30^{23}$. Pero la serie de acuarelas y dibujos que guarda la Biblioteca Nacional son apuntes, ensayos de un amateur refinado, que no alcanzan una propuesta coherente, integrada en su momento al sistema del arte peruano ${ }^{24}$.

Puede llamar la atención esta declaración mía pero quisiera que me concedan unos minutos para explicarla. En Lima, como en otras partes del mundo, el amateurismo fue una actitud muy difundida; por ejemplo, el uso de la acuarela y el paisajismo se extendieron notablemente dentro de la aristocracia y la clase media por ser una técnica que podía practicarse en casa, con o sin maestro, muy de acuerdo con los ideales educativos del siglo XIX, es decir, el cultivo del espíritu a través del amor a la naturaleza. Su práctica más libre, la ponía al alcance de mucha gente que no buscaba una profesión sino "cultivar el espíritu" y entretenerse sanamente. Por otro lado la idea fuertemente arraigada de que poetas, pintores y músicos eran considerados como bohemios, desanimaba las vocaciones artísticas y les vetaba el ingreso a estas profesiones. Allá por el año 1920, el caso de Miguel Miró Quesada, perteneciente a la aristocracia limeña, es interesante: se podía presentar en las exclusivas veladas capitalinas como bailarín aficionado, pero nunca como profesional; bailar era considerado como un adorno de su persona y permitido por su clase. Costumbre

20 Westphalen, Emilio A. Op. cit. p.174 y 296.

21 Coyné, André. El arte empieza donde termina la tranquilidad. En "Con los anteojos de azufre. César Moro artista plástico", catálogo de la exposición organizada por el Centro Cultural de España, con la curaduría de Rodrigo Quijano, Lima, 2000.

22 Westphalen, Emilio A. Op. cit. p. 318.

23 En el arte universal el caso de Víctor Hugo puede ilustrarnos al respecto con su serie de acuarelas que se guardan en la casa museo de París, que pueden ser consideradas como una curiosidad y documentos ligados a la vida del escritor sin pretensiones de reclamar un capitulo en las artes plásticas francesas.

24 La defensa cerrada que hace Westphalen de la condición de pintor de Moro se basa en el error teórico que confunde el sentido estético (común a casi todos los mortales) y el oficio artístico (entendido como tejné) practicado por los artistas. Así Moro, poseedor de una gran sensibilidad (gusto, estética, etc.) carecía, sin embargo, del oficio necesario para plasmar en imágenes pictóricas sus fantasías. En el caso de Eguren, su ausencia del circuito de las artes lo hizo casi inexistente como pintor en su momento. ("No me gusta el arte indigena", declaró alguna vez. Ver Wuffarden, 1997). 
que perduró en Lima hasta bien entrado el siglo XX, en el que se dio el caso de la fundación de una institución como la AAA (1938), donde se hacía buen teatro y buena danza pero, hechos por aficionados. Las jovencitas de la alta sociedad hacían ballet porque esta disciplina, aunque demasiado exigente, servía para su formación corporal y les confería cierta distinción y elegancia. Pero llegó el momento en que algunas profesoras y alumnas reclamaron la profesionalización y se les negó, teniendo que emigrar a otras escuelas o fundar las suyas.

En el caso de la música, era muy frecuente que los jóvenes, especialmente las mujeres, fueran sometidos por los padres a la disciplina del piano, no con miras a convertirse en profesionales, sino como aficionados. Con la creación de la Orquesta Sinfónica Nacional (1938) y el Conservatorio Nacional de Música (1946) se esclarece el problema: las vocaciones musicales tendrán un lugar donde estudiar y formarse, y donde trabajarán más tarde como músicos. El amateur (nunca mejor utilizado el apelativo) podrá asistir como escucha a las salas de concierto.

En fin, para terminar, habría que agregar que Westphalen estaba dotado de una inteligencia brillante unida a una exacerbada sensibilidad que algunas veces lo paralizaba, pero que daba lo mejor de sí en el trato afectivo con sus amigos más próximos. Hombre tímido y sensible, sin embargo, arremetió con fuerza, en sus dos primeros poemarios, contra la poesía tradicional, con una osadía que sólo Vallejo había demostrado, ${ }^{25}$ y denunció a ciertos individuos, los críticos literarios, cuyas "prácticas de mal aguiero (...) usos carentes de resonancias fecundas de cualquier especie, (...) estafa desvergonzada, (que) lleva (el) nombre, en muchos países, de "crítica de poesía"26.

Westphalen practica una crítica subjetiva, dentro de lo acostumbrado en el medio cultural limeño, con una intención bien clara: informar al público sobre la aparición del arte moderno y contemporáneo, en especial el Surrealismo. En este sentido dedicó una buena parte de sus artículos a temas literarios y, en menor número, a las artes plásticas pero, a través de todo el conjunto, se puede apreciar su convencimiento de que la creación, tanto poética como plástica, es una corriente inconsciente que sale de lo profundo del ser y "es casi invariablemente lo inesperado lo que nunca tuvimos sospecha que existía - la dádiva recaída sobre quien menos se esforzó en recibirla", idea que da origen a su creencia de que el poeta no es más que el "transcriptor" de ciertas imágenes y emociones. Por otro lado Westphalen se esmera en explicar su desvinculación de las ideas políticas del surrealismo, sobre todo en relación a la ideología cercana al marxismo que le hicieron ver los escritos de Paalen ${ }^{27}$.

La obra crítica de Westphalen abrió rutas nuevas, sembró inquietudes y dejó terrenos inexplorados, como era natural, para que otras generaciones más tarde dijeran su palabra. Por eso quisiera terminar con una frase que da fin a un artículo suyo: "Temo que sean numerosas las deficiencias de mi exposición y vano mi propósito de elucidación. Pero la tarea del crítico debe limitarse necesariamente a los aledaños y tierras marginales. No podía por tanto mi ambición ser otra sino remover algunos equívocos y facilitar el acceso". 25 "Habría que aceptar que la timidez no excluye obrar en ocasiones con independencia y desenvoltura".
Westphalen Emilio A. 2004. "Conversaciones con Nedda Anhalt", en Poesía completa y ensayos escogidos. Lima: Pontificia Universidad Católica del Perú. p. 641.

26 Op. cit. p. 28.

27 Westphalen Emilio A. 1996. "La teoría del arte moderno", en Escritos varios sobre arte y poesía, Lima: Fondo de Cultura Económica. p. 235. 